\title{
KIAT MERINTIS WIRAUSAHA PERTANIAN DI INDONESIA
}

\author{
Legi Aleksa \\ Universitas Nahdlatul Ulama Sidoarjo
}

\section{Pendahuluan}

Sekarang adalah saat yang tepat untuk memulai bisnis pertanian di Asia khususnya Indonesia. Pasar ceruk untuk produk pertanian mulai dari susu sapi hingga sayur yang diproduksi di gudang menciptakan peluang bagi petani muda dan pemula untuk melarikan diri dari dunia pekerja dan terlibat dalam industri pertanian yang mereka sukai. Menjadi sukses sebagai petani muda dan pemula tidaklah mudah. Program kementerian pertanian pemerintah $\mathrm{RI}$ berusaha membantu petani muda membangun bisnis mereka melalui pembiayaan awal, konsultasi manajemen bisnis, dan bimbingan. Program tersebut diharapkan dapat membantu para petani muda yang mungkin tidak memiliki catatan panjang dalam mengelola bisnis pertanian membangun jejak mereka di industri bisnis pertanian.

Dunia dan masyarakat membutuhkan kewirausahaan (Setyawati, Purnomo, Irawan, Tamyiz, \& Sutiksno, 2018). Tanaman adalah tumbuhtumbuhan yang biasa ditanam dan dipelihara (Javandira, Purnomo, \& Rosyidah, 2018). Berikut adalah beberapa kiat untuk dipertimbangkan jika Anda ingin memulai bisnis wirausaha pertanian di Indonesia.

\section{Dapatkan pendidikan finansial Anda}

Ini tidak selalu berarti pendidikan universitas formal. Kembangkan kebiasaan finansial yang baik sehingga Anda dapat menumbuhkan laporan kredit yang positif. Misalnya, Anda akan memiliki lebih banyak peluang jika Anda dapat menunjukkan bahwa Anda akan membayar utang saat jatuh tempo. Laporan kredit yang bagus menunjukkan calon investor atau mitra bisnis Anda seseorang yang dapat mereka percayai, dan mereka akan lebih bersedia untuk berdiri di samping Anda (Weaver, 2019). Manajemen adalah proses mengarahkan atau menjalankan bisnis, serta. sekelompok manajer atau direktur (Purnomo, Putri, \& Rosyidah, 2017).

\section{Bicara tatap muka dengan petani sebanyak mungkin}

Pebisnis pertanian sukses telah mengatur pertemuan makan siang yang tak terhitung jumlahnya dan obrolan kopi dengan petani untuk belajar tentang operasi mereka. Dia ingin mengatakan kepada mereka bahwa dia tidak ingin menjual apa pun kepada mereka, hanya untuk mengetahui 
tentang operasi mereka dan bagaimana mereka sampai di tempat mereka sekarang. Sebagian besar petani tidak sering mendapatkan permintaan semacam ini, dan lebih dari senang untuk berbagi (Hammerich, 2018). Sering kelapang akan dekat dengan petani, misal kala riset etnobotani. Pendekatan etnobotani berguna untuk mencegah hilangnya pengetahuan tanaman medis karena memiliki peran penting dalam menjaga kesehatan masyarakat (Zikri et al., 2018).

\section{Mendapatkan dana}

Jika - seperti kebanyakan petani kecil - Anda belum mewarisi pertanian, mencari uang untuk belajar bagaimana memulai pertanian, dan untuk mengubah impian Anda menjadi kenyataan, akan menjadi bagian inti dari strategi masuk ke pasar Anda.

\section{Teliti pilihan pendanaan Anda}

Riset Cornell University untuk merencanakan dan mendanai bisnis pertanian Anda adalah tempat yang baik untuk memulai. Ini akan memandu Anda melalui berbagai opsi pembiayaan, termasuk opsi pembiayaan mandiri. Apa yang tidak dilakukan adalah merekomendasikan Anda mengambil pinjaman kartu kredit. Faktanya, panduan ini secara khusus menyarankan bahwa ini adalah satu hal yang tidak Anda lakukan, karena Anda akan lebih baik berinvestasi setiap keuntungan langsung ke peternakan, dan jika Anda tidak membayar kembali pinjaman dengan cukup cepat, minat Anda Tingkat akan lepas kendali. Yang mengatakan, pastikan untuk bersikap realistis ketika Anda awalnya mengajukan permohonan untuk pendanaan. Jika Anda dapat menghindari membeli peralatan mahal di awal, lakukanlah. Memulai pertanian kecil adalah banyak pekerjaan fisik dan ada sedikit peralatan yang tersedia untuk membantu petani dalam skala kecil sehingga banyak pekerjaan dilakukan dengan tangan. Setelah bisnis Anda lepas landas, Anda dapat membeli hal-hal yang akan membuat hidup lebih mudah. Dan bahkan jika Anda tidak memiliki banyak uang tunai di masa mendatang, bank akan lebih cenderung memberi Anda pinjaman jika mereka melihat Anda menjalankan operasi yang menguntungkan (Landau, 2019).

\section{Tulis rencana bisnis}

Bagi siapa pun yang mencari pinjaman, menulis rencana bisnis akan menjadi sangat penting. Ini tidak berbeda dengan calon pemilik peternakan. Bahkan jika Anda tidak mencari pinjaman, rencana bisnis adalah alat yang berguna untuk membantu Anda mengetahui ide mana yang layak, dan untuk mengingatkan Anda tentang tujuan Anda. Anda dapat mengetahui lebih lanjut tentang menulis rencana bisnis di halaman Panduan 
Perencanaan Bisnis kami. Jika memvalidasi ide bisnis Anda lebih menarik bagi Anda daripada mendanai pada tahap ini, Anda mungkin lebih memilih untuk memilih Lean Plan - atau proses perencanaan yang lebih pendek dan lebih gesit. Tidak yakin bagaimana memformat rencana bisnis pertanian Anda? Lihatlah perpustakaan kami dari rencana bisnis sampel khusus pertanian, termasuk rencana bisnis pertanian buah, rencana bisnis tanaman keras botani, rencana pasokan pakan dan pertanian, rencana bisnis hidroponik, dan banyak lagi!. Jelas, sebelum Anda duduk untuk menulis rencana bisnis Anda, Anda harus menentukan biaya produksi. Anda juga perlu tahu berapa biaya sewa / sewa Anda (Landau, 2019).

\section{Prioritaskan perencanaan suksesi}

Sudahkah suksesi dibahas dan disetujui bersama keluarga yang lebih luas? Apakah Anda tahu, dan apakah Anda sudah membahas dengan anggota keluarga tujuan pribadi dan bisnis mereka?. Jangan anggap Anda tahu apa yang diinginkan orang lain di masa depan. Apakah kehendak Anda terkini? Apakah Anda memiliki perjanjian kemitraan tertulis? Apakah itu berisi klausa kelanjutan yang memungkinkan bisnis untuk melanjutkan perdagangan dan agar rekening bank tetap beroperasi pada saat kematian salah satu mitra. Meskipun ini adalah kemungkinan yang kami tidak ingin pikirkan, mereka sangat penting untuk memungkinkan bisnis agar tetap berfungsi jika terjadi sesuatu pada personel kunci. Dapatkan disortir sekarang dan selesai (McLean, 2019).

\section{Investasikan di seluruh rantai nilai pertanian}

Bisnis pertanian luas dan mencakup segala sesuatu mulai dari budidaya tanaman hingga pemeliharaan hewan, produksi wol untuk pakaian, dan bahan untuk perumahan. Barang-barang kulit seperti tas, sepatu, sepak bola, bola basket, bola voli, dan sarung tangan terbuat dari kulit sapi, jadi ada banyak area yang bisa Anda investasikan. Oleh karena itu, ada berbagai cara investasi dapat dilakukan dan beberapa di antaranya adalah melalui (Ekong, 2019):

- Tanah pertanian: Apresiasi tanah menjadikan tanah pertanian salah satu area terbaik untuk investasi. Pengurangan konstan karena proyek rumah dan pabrik membuat tanah yang tersedia jauh lebih berharga. Faktor apresiasi ini bermanfaat bagi investor.

Jika Anda ingin berinvestasi di lahan pertanian yang subur, Anda dapat membeli sebidang luas lahan pertanian dan bekerja dengan petani setempat untuk bertani.

- Stok pertanian: Investasi dapat berwujud (tanah pertanian, budidaya hewan, dII) atau tidak berwujud (stok). Anda dapat berinvestasi dalam 
persediaan perusahaan persediaan dan peralatan pertanian dengan membeli saham.

- Exchange Traded Funds: Sama seperti saham, Exchange Traded Funds adalah dana investasi yang diperdagangkan di bursa efek. Dianggap kurang stabil daripada saham individual, dan lebih murah daripada kebanyakan saham minimal, ETF melacak indeks saham, komoditas, obligasi, atau sekeranjang aset.

Dalam agro-bisnis, ETF dapat mengelompokkan aset seperti kontrak berjangka untuk tanaman yang berbeda atau kontrak untuk satu tanaman dari petani yang berbeda. Keuntungan dapat diperoleh dari membeli dan menjual saham ETF.

- Futures: Futures adalah kontrak keuangan yang mewajibkan pembeli untuk membeli aset atau penjual untuk menjual aset pada tanggal dan harga masa depan yang telah ditentukan. Futures menawarkan investor cara mudah untuk memainkan perubahan harga untuk produk pertanian tanpa benar-benar memiliki aset yang mendasarinya.

Berjangka dapat dibeli dalam kedelai, kakao, kopi, jagung, kapas, dan produk pertanian lainnya. Kontrak untuk masa depan mungkin sulit untuk dipahami dan karenanya, opsi ini paling direkomendasikan untuk investor berpengalaman atau mereka yang akrab dengan siklus pertanian.

- Bioteknologi: Teknologi berada di garis depan semua sektor dan pertanian tidak ketinggalan. Dengan tingginya permintaan pangan, petani mencari cara untuk meningkatkan praktik pertanian dan produksi tanaman.

Penerapan biologi pada pertanian dapat memungkinkan pengembangbiakan tanaman dengan ketahanan yang kuat terhadap hama, tanaman dengan karakteristik yang lebih baik, pemrosesan pasca panen yang lebih baik, serta mitigasi pencemaran lingkungan. Investor dapat membeli saham di startup biotek.

Meskipun investasi dalam biotek bisa sangat berisiko, ia menawarkan potensi untuk keuntungan besar jika berhasil.

- Crowdfunding: Internet telah meningkatkan popularitas crowdfunding bahkan di sektor pertanian dan telah menjadikan investasi agro-bisnis buah yang rendah bagi investor yang cerdas. Platform crowdfunding Agro seperti Farmcrowdy memungkinkan investor untuk berinvestasi di unit pertanian, memantau kemajuan, dan mendapatkan $\mathrm{ROI}$ setelah siklus pertanian selesai.

\section{Rencanakan ke depan}

Para pebisnis pertanian sukses juga menyarankan agar petani mempertimbangkan untuk melakukan audit bisnis untuk memahami sumber daya yang tersedia dalam bisnis. Bertani mungkin menjadi landasan bisnis Anda, tetapi pertimbangkan apa lagi yang bisa Anda dan perusahaan Anda 
lakukan untuk mencapai pengembalian terbaik dari aset Anda. Ingat, apa yang mungkin bukan peluang sekarang, mungkin dalam lima tahun ke depan dan karenanya perlu menyelidiki ini sekarang untuk maju dari pasar. Ini juga sama pentingnya untuk memahami apa sumber daya yang membatasi (termasuk modal) dalam bisnis, mengapa demikian, dan tindakan apa yang dapat diambil untuk bekerja dengan atau mengatasi keterbatasan ini (McLean, 2019). Salah satu agribisnis menarik adalah budidaya melon semangka dengan hidroponik. Hidroponik berasal dari kata hydro yang berarti air dan Phonic yang berarti pengerjaan. Sehingga secara umum pengertian hidroponik yaitu sistem budidaya pada pertanian tanpa menggunakan tanah liat sebagai bahan menanam (Munjidah et al., 2018). Hidroponik sistem terapung non sirkulasi sudah berhasil diaplikasikan pada tanaman sayur (Maghfoer, Moch. Dawam; Wardiyati, Tatik; Purnomo, 2007). Buah melon dan semangkan dapat dibentuk kotak (Purnomo, Agung; Rosyidah, 2010).

\section{Penutup}

Kiat untuk merintis wirausaha pertanian di Indonesia yakni bicara dengan petani, pendidikan finansial, dapatkan dana, investasi value chain, rencanakan kedepan, dan rencana suksesi.

\section{References}

Ekong, U. (2019). 7 Tips for Investing in an Agro Business. Retrieved December 21, 2019, from https://blog.farmcrowdy.com/investing-inagro-business $/ \% 0 \mathrm{~A}$

Hammerich, T. (2018). 10 Tips For Getting Started in Farming. Retrieved December 20, 2019, from https://futureofag.com/10-tips-for-gettingstarted-in-farming-b410520a6f50

Javandira, C., Purnomo, A., \& Rosyidah, E. (2018). Kamus Pertanian. Sidoarjo: UNUSIDA Press.

Landau, C. (2019). How to Start a Farm: Your Complete Guide to Success. Retrieved December 22, 2019, from

https://articles.bplans.com/how-to-start-a-farm-and-how-to-startfarming/

Maghfoer, Moch. Dawam; Wardiyati, Tatik; Purnomo, A. (2007). Pengaturan Jarak Panel dengan Permukaan Media pada Teknik Hidroponik Sistem Terapung Tanaman Melon. Agrivita, 29(Khusus), 388-396.

McLean, R. (2019). Top Ten Agriculture Business Tips for Farmers. Retrieved December 22, 2019, from https://www.thebusinessbarn.co.uk/rural-business-ideas-andinspiration/rural-business-discussion-topics/top-ten-business-tips-forfarmers/ 
Munjidah, A., Nahdiyah, K., Maula, I., Asitah, N., Yuniarti, D., Sholichah, S. A., ... Achmadi, A. K. (2018). Hidroponik: 5 Premis Rekognisi Bagi Pemula. Retrieved from https://osf.io/preprints/inarxiv/hwnvr/

Purnomo, Agung; Rosyidah, E. (2010). Rumah Kotak Tumbuh bagi

Keluarga Semangka. In 102 Inovasi Indonesia (pp. 58-59). Jakarta:

Business Innovation Center.

Purnomo, A., Putri, R. A., \& Rosyidah, E. (2017). Kamus Manajemen

Sumber Daya Manusia. Sidoarjo: UNUSIDA Press.

Setyawati, I., Purnomo, A., Irawan, D. E., Tamyiz, M., \& Sutiksno, D. U. (2018). A Visual Trend of Literature on Ecopreneurship Research Overviewed within The Last two Decades. Journal of Entrepreneurship Education, 21(4), 1-7. Retrieved from https://www.abacademies.org/articles/a-visual-trend-of-literature-onecopreneurship-research-overviewed-within-the-last-two-decades7468. html

Weaver, L. (2019). 5 Tips for Starting a New Ag Business. Retrieved December 23, 2019, from https://www.farmcrediteast.com/knowledgeexchange/Blog/todays-harvest/5-tips-for-starting-a-new-ag-business

Zikri, M., Sumartono, E., Novanda, R. R., Parwito, P., Purnomo, A., Busro, B., \& Supriyono. (2018). Ethnobotany of Medical Plants by Rejang Selupu Ethnic. Journal of Physics: Conference Series, 1114(1), 012130. https://doi.org/10.1088/1742-6596/1114/1/012130 